\title{
Studi Komparasi: Penerapan E-Government Di Korea Selatan Dan Indonesia
}

\author{
Diah Wahyuningsih ${ }^{1}$, Eko Priyo Purnomo \\ ${ }^{1,2}$ Magister Ilmu Pemerintahan, Universitas Muhammadiyah Yogyakarta, Indonesia \\ Korespondensi*: Diahwahyuningsih918@gmail.com
}

\begin{abstract}
ABSTRAK
Studi ini membahas perbandingan penerapan e-government di negara Korea Selatan dan Indonesia. Tujuan penulisan ini adalah untuk mendeskripsikan penerapan e-government di Korea Selatan dan Indonesia, serta membandingkan penerapannya dan dampaknya terhadap pemberantasan korupsi di di kedua negara tersebut. Selain itu penulis juga merekomendasikan pengembangan e-government yang baik di Indonesia, melihat dari best practice e-government Korea Selatan. Penelitian ini menggunakan metode penelitian studi literatur, penelitian dengan studi literatur tidak harus turun ke lapangan dan bertemu dengan responden. Penelitian ini persiapannya sama dengan penelitian lainnya akan tetapi sumber dan metode pengumpulan data dengan mengambil data di pustaka, membaca, mencatat, dan mengolah bahan penelitian. Hasil dari penulisan ini menjelaskan perbandingan perkembangan penerapan e-government di Kedua Negara tersebut dan dampaknya terhadap pemberantasan korupsi dan tata kelola pemerintahan.
\end{abstract}

Kata kunci: E-Government, Korea Selatan, Indonesia.

\begin{abstract}
This study discusses the comparison of the application of e-government in South Korea and Indonesia. The purpose of this paper is to describe the implementation of e-government in South Korea and Indonesia, and to compare its application and its impact on combating corruption in both countries. In addition, the authors also recommend the development of good e-government in Indonesia, looking at the best practices of South Korean e-government. This research uses the method of research literature studies, research with literature studies do not have to go to the field and meet with respondents. This research is the same preparation as other studies but the sources and methods of data collection by taking data in the library, reading, recording, and processing research materials. The results of this paper explain the comparative development of the implementation of e-government in the two countries and their impact on the eradication of corruption and governance.
\end{abstract}

Keywords: Comparison, Implementation, E-Government.

\section{PENDAHULUAN}

Salah satu bentuk perkembangan zaman yang berjalan sangat pesat adalah teknologi. Semakin berkembangnya teknologi membuat hal-hal yang dahulu dikerjakan secara manual dan membutuhkan waktu yang lama saat ini menjadi mudah dan ceapat. Internet adalah salah satu teknologi yang paling berkembang.

Dengan adanya internet dapat membantu memenuhi kebutuhan informasi pada masyarakat. Sehingga kemudahan 
mendapatkan informasi yang cepat, tepat dan akurat menjadi hal yang mudah saat ini. Penggunaan teknologi informasi saat ini sudah diterapkan diberbagai bidang, salah satunya di bidang Pemerintahan. Dalam penyelenggaraan pemerintahan penggunaan teknologi informasi disebut dengan istilah E-government (Fadillah, 2017).

Melalui E-Government seluruh lembaga-lembaga negara, dunia usaha, masyarakat dan pihak-pihak yang berkepentingan lainnya dapat setiap waktu memanfaatkan informasi dan layanan pemerintah secara optimal.

Penggunaan teknologi dalam penerapan e-gov merupakan sebuah upaya yang dilaksanakan oleh lembaga pemerintahan dalam mengoptimalkan penyediaan jasa layanan bagi masyarakat. Selain itu penggunaan e-gov juga berusaha membuat penyelenggaraan pelayanan publik lebih efektif dan efisien dari segi penggunaan waktu, anggaran, dan penerapan hubungan atau relasi yang mudah.

Penerapan inovasi e-government sendiri sudah telah banyak dilakukan di seluruh Indonesia namun dengan tingkat keberhasilan yang beragam. E-Government dalam penerapannya tidak hanya sekedar menggunakan teknologi semata tetapi harus didukung dengan regulasi dan kebijakan yang baik pula.
Beberapa permasalahan yang menjadi penyebab gagalnya pengembangan dan penerapan e-government adalah ketidaksiapan sumberdaya manusia, teknologi informasi yang tersedia, budaya organisasi pemerintah, serta kurangnya perhatian dari pihak-pihak yang terlibat secara langsung.

Korea Selatan merupakan salah satu negara terbaik dalam menerapkan egovernment berdasarkan penilaian dari PBB. Beberapa e-government di Korea Selatan menjadi best practice e-government yang dijadikan sebagai percontohan penerapan e-government di dunia.

Negara ini selalu masuk dalam 10 terbaik penerapan e-Government di dunia. Penerapan e-Government di Korea juga berdampak pada pemberantasan korupsinya.

Di Indonesia beberapa daerah sudah dikatan cukup baik dalam menerapkan eGovernment, seperti Kabupaten Seragen, Kota Surabaya. Tak hanya di Korea Selatan saja yang penerapan e-governmentnya berdampak baik terhadap pemberantasan korupsi, Indonesia pun demikian karena egovernment dapat meningkatakan transparansi publik.

Dari paparan diatas menarik untuk diidentifikasi, dianalisis dan membandingkan bagaimana perbandingan penerapan e-Government di negara maju 
seperti Korea Selatan dan Negara berkembang Indonesia serta bagaimana dampak e-government dalam terhadap korupsi di kedua negara tersebut.

\section{METODE}

Penelitian ini menggunakan metode penelitian studi literatur, penelitian dengan studi literatur tidak harus turun ke lapangan dan bertemu dengan responden. Penelitian ini persiapannya sama dengan penelitian lainnya akan tetapi sumber dan metode pengumpulan data dengan mengambil data di pustaka, membaca, mencatat, dan mengolah bahan penelitian.

Data-data yang dibutuhkan dalam penelitian diperoleh dari sumber pustaka penelitian terdahulu yang membahas terkait dengan e-government serta data yang valid dari website egovernment pemerintah Korea Selatan dan beberapa website e-government pemerintah daerah yang ada di Indonesia.

Analisis data serta kesimpulan yang dihasilkan sesuai dengan tujuan yang diharapkan. Dalam menulis artikel ini penulis menelaah dan menganalisis 21 jurnal terkait dengan e-government. Hasil dari berbagai literatur ini akan digunakan penulis untuk membahas dan mengkomparasikan penerapan egovernment di dua negara tersebut.

\section{HASIL DAN PEMBAHASAN}

\section{Penerapan E-Government Di Korea Selatan}

Salah satu Negara yang cukup berhasil menerapkan e-Government adalah Korea Selatan. Negara ini selalu masuk dalam 10 terbaik penerapan e-Government di dunia. Korea Selatan sudah membuat undangundang e-government yang tujuannya agar dapat diterapkan guna meningkatkan efisiensi pada semua urusan administrasi pemerintahan dan meningkatkan semua kualitas pelayanan publik.

Dengan memanfaatkan teknologi informasi, pemerintah Korea Selatan memperbaki transparansi dan meningkatkan efisiensi administrasi dengan reformasi metode kinerja pemerintah. Dimulai pada tahun 2008, Pemerintah Korea Selatan mulai mengintegrasikan seluruh sistem e-government. Berbagai proyek diterapkan dan pemerintah mulai memfokuskan koneksi untuk menciptakan teknologi infomasi yang handal dan baik demi mengintegrasikan seluruh pelayanan publik. Jenis E-Government di Korea sangat beragama, namun disini penulis hanya akan membahas beberapa saja. Berikut ini merupakan jenis e-government di Korea Selatan: 


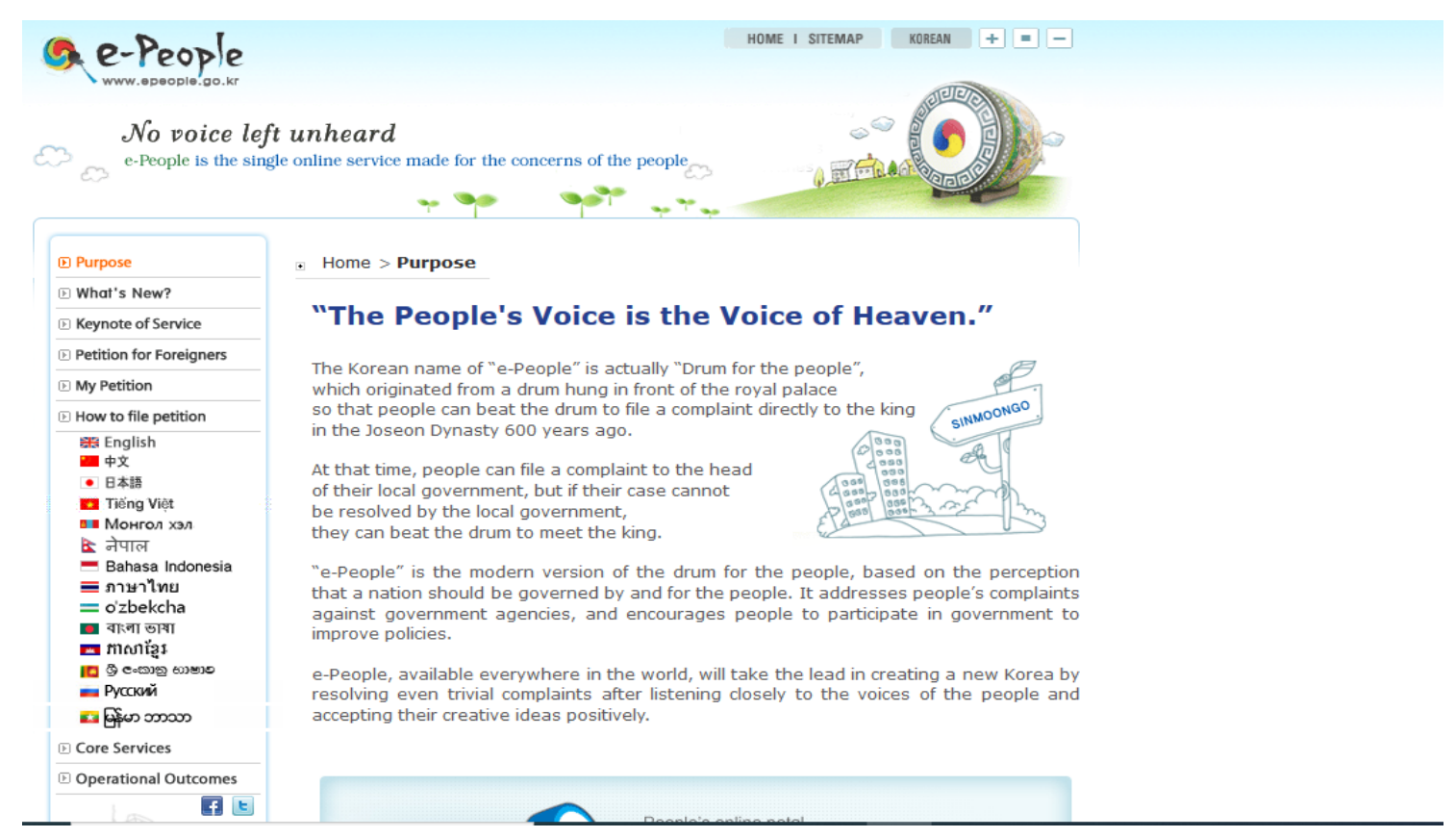

Gambar 1 Beranda E-People

Sumber https://www.epeople.go.kr/jsp/user/on/eng/intro01.jsp

E-Participation Portal - ePeople : https://www.epeople.go.kr.

E-Participation adalah bentuk egovernment yang dikembangkan oleh Pemerintah Korea Selatan untuk dapat menilai kualitas dan kegunaan informasi dan berbagai layanan publik yang disediakan oleh sebuah negara yang bertujuan melibatkan masyrakatnya dalam membuat kebijakan publik melalui pemanfaatan berbagai program eGovernment. Masyarakat Korea Selatan dapat menyamapaikan kritik, saran dan keluhannya melalui website ini dan aspirasi yang mereka sampaikan dapat mempengaruhi pengambilan keputusan Pemerintah.

Postal Logistics Information SystemPostNet: https://www.epost.go.kr.

E-Post merupakan website yang disediakan dan dikelola oleh Pemerintah untuk mengirim surat dan Paket. Di Indonesia model tersebut seperti layaknya POS Indonesia. Webiste ini tersedia dalam dua bahasa, yaitu Bahasa Korea dan Bahasa Inggris yang memudahkan masyarakat yang mengaksesnya.

Situs ini menawarkan layanan pos dengan nyaman dan aman seperti Pos, Pengiriman, EMS Belanja, Pasar terbuka yang dapat diakses kapan pun dan 
dimanapun tanpa perlu mengunjungi kantor pos. Untuk dapat menggunakan layanan ini masyarakat harus mempunyai ID dan kata sandi.
E-post dapat diakses 24 jam nonstop, sehingga berbagai kebutuhan paket dan surat masyarakat dapat diselesaikan dengan aman dan nyaman.

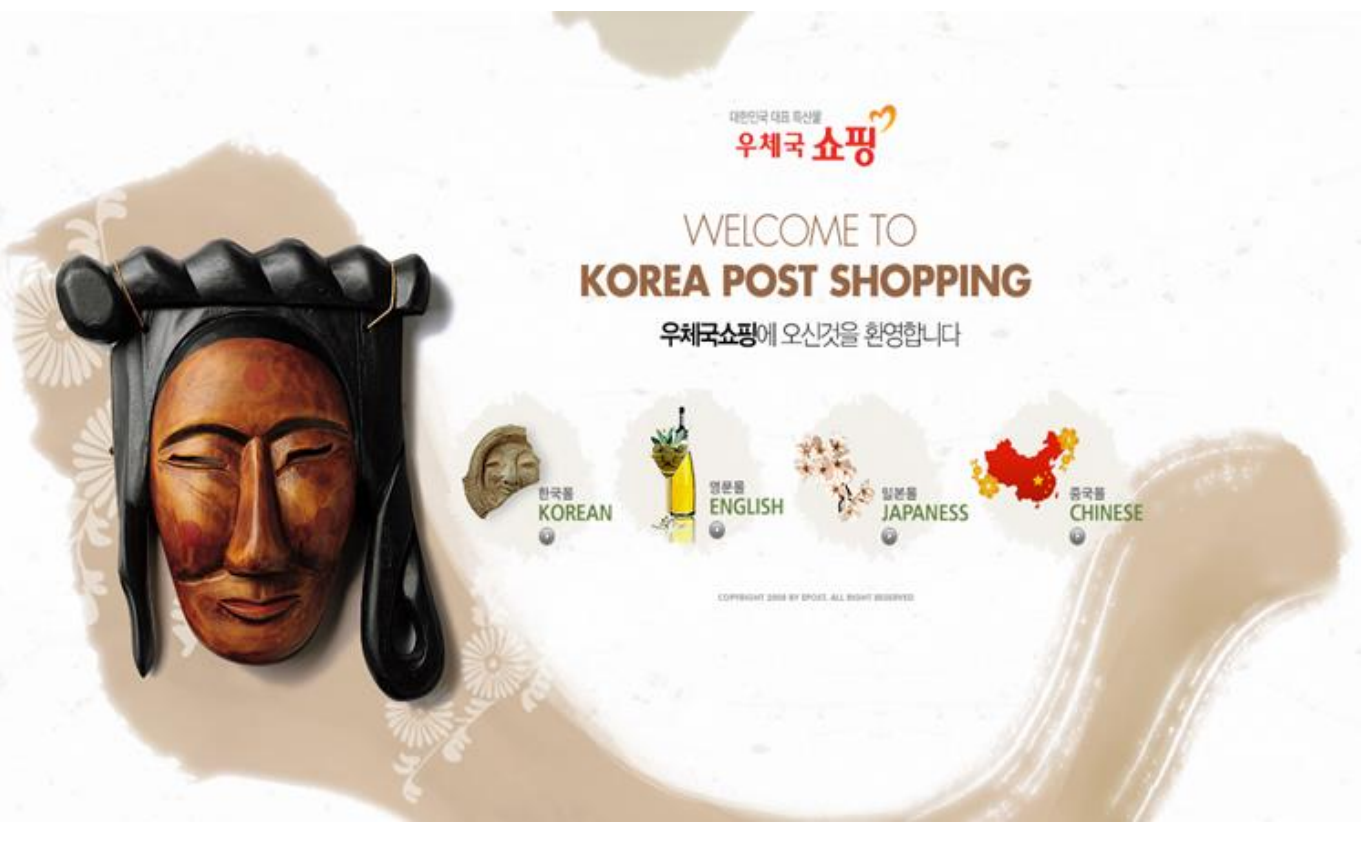

Gambar 2

Sumber https://mall.epost.go.kr/intro.html

Employment Portal (Worknet) : website tersebut karena website ini https://www.work.go.kr menampung seluruh data dan informasi Webiste ini menyediakan berbagai karyawan yang ada di seluruh perusahaan informasi lowongan pekerjaan yang yang ada di Korea Selatan. Dengan adanya dibutuhkan oleh seluruh masyarakat Korea website tersebut websiter tersbut ternyata Selatan. Masyarakat hanya tinggal dapat mengurangi angka pengangguran di mengakses websiter tersbut dan mencari pekerjaan yang diinginkan. Untuk Korea Selatan. Pada tahun 2019 jumlah tingkat pengangguran di Korea Selatan perusahaan yang akan mencari informasi berkisar di angka $3.8 \%$.

data karyawan juga dapat mengakses 
Lihat Tingkat Pengangguran Korea Selatan dari 1999-06 sampai 2019-12 pada grafik:

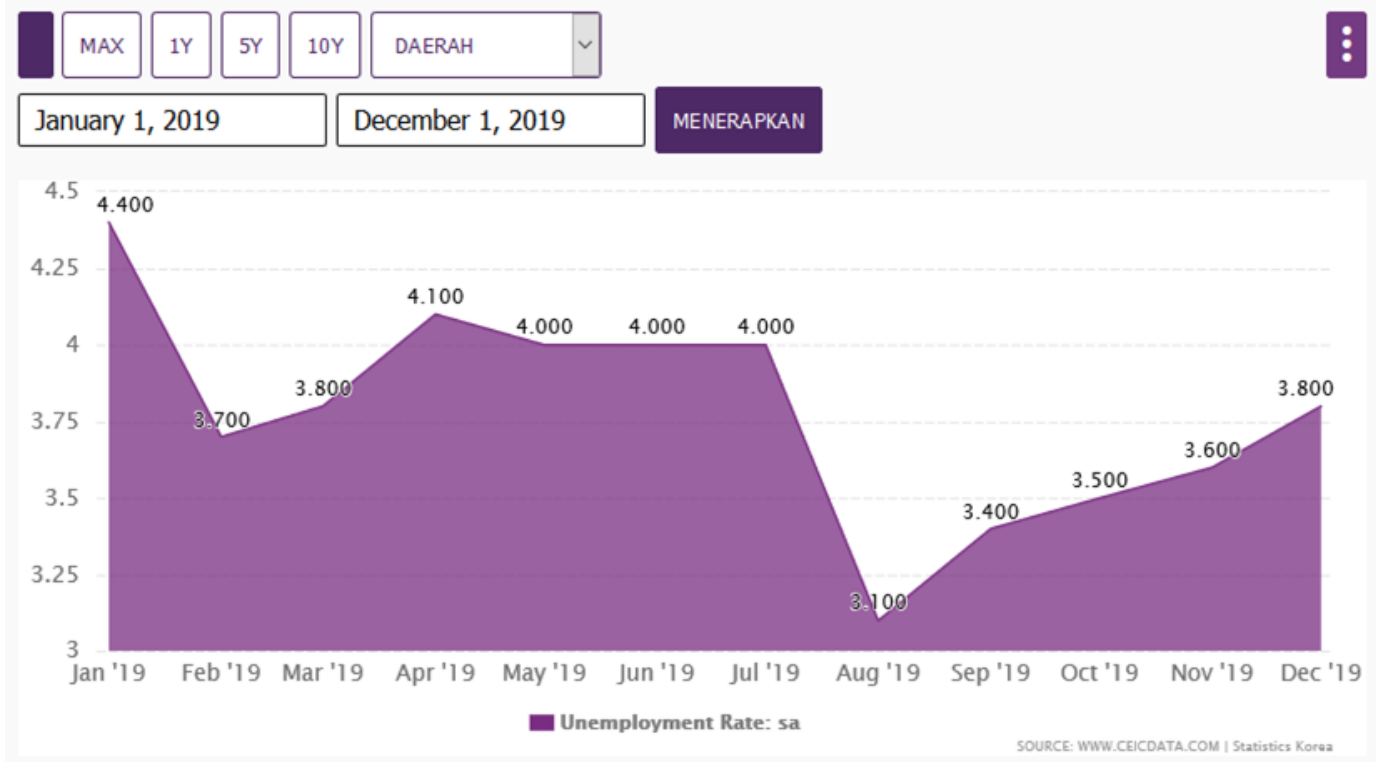

\section{Gambar 3 Tingkat Pengangguran Di Korea Selatan Tahun 2019 Sumber www.ceicdata.com}

Di Korea Selatan E- Government dapat digunakan untuk memberantas korupsi. Di Kota Seoul terdapat sistem OPEN yang merupakan strategi antikorupsi dan menjadi salah satu komponen penting dalam e-government. Dengan sistem OPEN ini membuat dampak besar terhadap transparansi publik untuk pengambilan keputusan dan tindakan individu PNS.

Masyarakat dapat melacak pengelolaan layanan, selain itu pengawas juga dapat melacak perilaku yang dianggap mencurigakan. Kedua pada beberapa departemen yang dicuragi korup, lebih ditingkatkan lagi pelayanan dan pengawasannya serta menargetkan transparansi.. E-government membuat data secara terpadu untuk diaudit dan dianalisis.
Informasi dari pemerintah dipublikasikan di website milik pemerintah berupa data dan dokumentasi sebagai bentuk akuntabilitas dan transparansi dalam merespon keluhan masyarakat terkait praktek korupsi. Korupsi seringkali adalah bentuk cerminan adanya kekuatan jarak antara aparatur pemerintah dengan masyarakat terutama masyarakat yang masih awam terkait dengan programprogram pemerintah.

\section{Penerapan E-Government di Indonesia}

Untuk menghadapi tantangan era globalisasi, pemerintah Republik Indonesia berinovasi membuat kebijakan memanfaatkan teknologi informasi dan komunikasi yang terintegrasi mulai dari tingkat pemerintahan daerah hingga ke 
pusat. Kebijakan pemerintah terkait pemaanfaatan teknologi informasi antara lain dituangkan dalam bentuk Inpres No.3 tahun 2003 dan keputusan Menteri Komunikasi dan Informasi tentang perkembangan e-Gov yang merupakan perencanaan pemerintah dalam menjalankan kebijakan-kebijakannya demi meningkatkan kesejahteraan rakyat. Meskipun penerapan E-Govrnement di Indonesia tidak sebaik dan secanggih egovernment di Korea Selatan, namun egovernment di Indonesia berusaha di perbaiki setiap saat sesuai dengan perkembangan zaman.

Pemerintah Indonesia telah mengembagkan Government Service Bus (GSB), yang bertujuan untuk menghubungkan server-server yang ada diKementrian/Lembaga/Satuan Kerja

\section{Penerapan E-Government di Kabupaten Seragen}

Kabupaten Sragen mengembangkan "One Stop Service (OSS)" melalui Badan Layanan Terpadu. One Stop Service Centre adalah sebuah institusi yang memberikan dukungan pengembangan satuan kerja layanan perijinan terpadu. Salah satu Dengan menerapkan OSS, pembuatan perijinan tidak lagi berbelit-belit karena

proses perijin cukup berhenti di satu atap(http://dpmptsp.sragenkab.go.id.).
Perangkat Daerah (www.kominfo.go.id). GSB mengintegrasikan data berbasisi Nomor Induk Pegawai dari Badan Kepegawaian Negara (BKN), Nomor Induk Kependudukan (NIK) dari server Kementrian Dalam Negeri (KEMENDAGRI) dan Nomor Pokok Wajib Pajak (NPWP) dari server Kementrian Keuangan. Dalam mengintegrasikan data tersebut menggunakan aplikasi SIMANTRA (Indrayani, 2016).

SIMANTRA adalah apalikasi manajemen pertukaran data pemerintah. Selain itu digunakan juga PNSbox (Privati Network Security) yang diinstal terlebih dahulu pada data center yang ada di Kementrian/Lembaga/Satuan Kerja Perangkat Daerah. Berikut ini adalah beberapa pemerintah daerah yang cukup berhasil dalam menerapkan e-Government

Selain itu, proses pelayanan yang sederhana memberikan kesan transparan yang memberi konsumen kepercayaan terhadap para karyawan dan institusi tersebut. OSS hadir berawal dari tingginya angka kompetisi bisnis baik di tingkat pusat maupun daerah. Terbentuknya OSS Center dapat memberikan pendampingan pada OSS daerah-daerah yang masih sangat membutuhkan. Manfaat dari adanya OSS ini adalah dapat melayani seluruh perizinan yang dibutuhkan oleh investor dan dunia usaha di berbagai daerah. OSS Center 
menyediakan beragam informasi serta pelatihan dalam mengembangkan layanan perizinan dan investasi di Indonesia (www.osscenter.net).

\section{Penerapan E-Government di Kota Surabaya}

Penerapan e-government Government di Kota Surabaya di bagi menjadi dua bagian, yang pertama yaitu dalam hal pengelolaan keuangan yang diwujudkan dalam bentuk e-budgeting, e-project, eprocurement, e-delivery, e-controlling, dan e-perfomance. Yang kedua dalam hal pelayanan public yang diwujudkan dalam eDengan hadirnya e-procurement ini maka Pemerintah dan masyarakat Kota Surabaya dapat dengan mudah mengetahui proses pengadaan barang dan jasa yang sedang berjalan (www.lpse.surabaya.go.id).

Penerapan e-procurement di Surabaya mendapatkan pengahargaan dari Kementrian Pendayagunaan Aparatur Negara dan Reformasi Birokrasi (KEMNPANRB) karena dinilai sudah cukup berhasil. Penerapan e-government tersebut oleh KEMENPANRB menjadi percontohan e-government bagi pemerinta daerah lainnya (https://menpan.go.id).

Selain itu Kota Surabya juga memiliki e-budgeting. E-budgeting hadir kareana permasalahan lambatnya penyusunan sapawarga yang didalamnya mencakup eperizinan, e-musrenbag, dan pengaduan.

E-procurement di Kota Surabaya merupakan inovasi manajemen pelayanan publik yang dikelola dengan memanfaatkan teknologi informasi yang efektif diterpakan mulai dari tahun 2006. E-Procurement hadir karena sistem pengadaan barang dan jasa yang masih dilakukan secara manual, sehingga kurang efektif dan efisien. Selain itu marak terjadinya korupsi dalam pelaksaaa barang dan jasa dengan sistem manual.

APBD serta besarnya kebocoran anggaran, ketika masih menggunakan sistem yang manual. Pada tahun 2012, seluruh SKPD yang ada di Kota Surabaya sudah terkoneksi dengan jaringan dengan menggunakan Fiber Optik, Wireless dan VPN.

\section{Penerapan E-Government di Kota Yogyakarta}

Dalam menerapkan e-government pemerintah Kota Yogyakarta membuat inovasi SI UPIK (Sistem Informasi dalam Unit Pelayanan Informasi dan Kel.uhan). SI UPIK diharapkan dapat menampung aspirasi, krikit, saran, dan masukan dari masyarakat. Asprasi masyarakat sangatlah penting bagi pemerintah dalam membuat dan mengevaluasi program-program yang tepat untuk mensejahterkan masyakarat. 
Inovasi SI UPIK berdasarkan Keputusan Walikota Yogyakarta No 86, tahun 2003. Beragam tuntutan masyarakat Kota Yogyakarta dipengaruhi dengan latar belakang sosialnya yang kritis.

Adanya SI UPIK berawal dari kegiatan pengadaan sistem dan pelatihan Sumber Daya Manusia dalam mengoperasikan teknologi informasi untuk menjembatani komunikasi antara masyarakat dengan Pemerintah daerah. Dari pengaadan tersebut dimenangkan oleh PT Exindo.

Pada waktu itu PT Exindo menawarkan kepada Pemerintah pemanfaatan teknologi sebagai sarana pengaduan yang paling banyak digunakan oleh masyarakat melalui short message service (SMS), telpon seluler maupun email. Sedangkan untuk softwarenya sendiri, kegiatan pelaksanaan pengadaannya dimonitoring langsung oleh Pemkot Kota Yogyakarta bekerja sama dengan Swisscontact.

UPIK dapat diakses di www.upik.jogja.go.id atau melalui email upik@jogja.go.id. Setelah inovasi SI UPIK ini diterapkan ternyata respon masyarakat sangat baik terbukti dengan banyaknya masyarakat yang menyampaikan keluhan, permasalahan, dan aduannya via sms. Ternyata dalam penerapan SI UPIK mengalami beberapa hambatan salah satunya adalah dua no operator tersebut hanya terbatas bagi pengguna kartu SIMPATI dan HALO pada saat itu.

Bagi masyarakat pengguna selain kartu dua kartu tersebut tentunya kesulitan dalam melakukan pengaduan. Akhirnya Pemerintah Kota Yogyakarta menjalin kerjasama dengan lembaga konsultan di salahs atu perguruan tinggi yaitu Gama Techno, sehingga semua operator ponsel telpon seluler dapat dijangkau SI UPIK dengan perluasan jaringan.

Pada akhirnya semua operator seluler dapat mengakses layanan aduan SI UPIK. Melalui evaluasi yang dilakukan oleh konsultan TI Pemerintah daerah Kota Yogyakarta bahwasannya aduan masyarakat sebagain besar melalui SMS, kemudian akhirnya dirancang berbagai fitur yang tepat dengan aduan yang masuk tersebut menggunakan sms.

Hal tersebut dimaksudkan agar ketika ada aduan yang masuk ke UPIK, masyarakat mendapat auto replay dari operator SI UPIK. Selanjutnya setiap masyarakat yang menyampaikan aduannya akan mendapatkan kode akses yang gunanya untuk melihar respon selanjutnya dari layanan SI UPIK.

Dengan banyaknya aduan yang masuk, akan di filter terlebih dahulu oleh petugas operator SI UPIK sesuai dengan aduan yang disampaikan. Petugas operator tentu akan 
memilih aduan masyarakat yang di rasa benar-benar serius dan harus segera ditangani, yan selanjutnya akan disampaikan ke instansi terkait yang menanganinya. Walikota mengamanatkan bahwasannya aduan yang masuk harus direspon $2 \times 24$ jam dalam prosesnya.

\section{Dampak E-Government Terhadap Korupsi Di Indonesia}

Sebagai negara berkembang Indonesia tidak terlepas dari masalah korupsi. Indeks Persepsi Korupsi Indonesia (IPK) Indonesia 2018 naik ke peringkat 4 di tingkat ASEAN setelah berhasil menggeser posisi Thailand yang turun ke posisi 6. Sebelumnya, posisi
2018 naik 1 poin menjadi 38 dari skala 0100. Sementara IPK Thailand turun 1 poin menjadi 36. Skor IPK Indonesia yang naik 1 poin membuat Indonesia kini berada di peringkat 89 dari 180 negara dari tahun sebelumnya di posisi 96. Sementara Thailand turun ke peringkat 99 dari sebelumnya 96.

Adapun Singapura masih menjadi negara paling bersih korupsi di kawasan Asia Tenggara dengan skor IPK 85 kemudian diikuti Brunei Darussalam (63) dan Malaysia (47). Sedangkan di urutan buncit dihuni Kamboja dengan IPK 20. IPK mendekati 0 mengindikasikan suatu negara

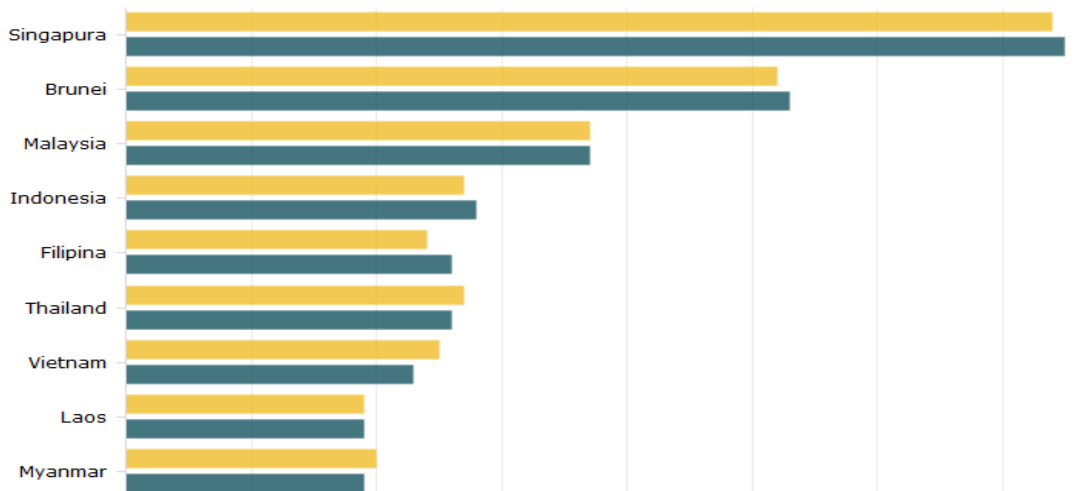

Indonesia berada di bawah Negeri Gajah banyak terjadi korupsi. Sebaliknya skor IPK Putih.

$$
\text { Hasil survei Transparency }
$$
mendekati 100 mengindikasikan semakin bersih dari korupsi.

International mencatat IPK Indonesia pada

\section{Gambar 6 Indeks Persepsi Indonesia (IPK)}

Sumber www.transparency.org

Dalam mewujudkan pemerintahan yang bersih dan transparan bebas dari Korupsi, Kolusi dan Nepotisme, Indonesia masih mempunyai banyak pekerjaan rumah yang perlu diselesaikan. Aparatur pemerintah mempunyai peran penting dalam melaksanakan berbagai aspek pemerintah mulai dai pendidikan, kesehatan, pelayanan 
masyarakat, administrasi, dan lain sebagainya. Namun yang terjadi dilapangan masih banyaknya permasalahan yang berkaitan erat dengan aparatur pemerintah terkait dengan korupsi, buruknya pelayanan kepada masyarakat, serta rendahnya akuntabilitas kinerja organisasi.

Tata kelola pemerintahan yang kurang baik mengakibatkan pelayanan publik yang

tidak efektif, lambat, tidak transparan, berbelit-belit, dan tidak efisien. Dari hal tersebut kekecewaan dan turunnya

\section{SIMPULAN}

Penggunaan teknologi dengan penerapan e-gov merupakan sebuah upaya yang dilaksanakan oleh lembaga pemerintahan dalam mengoptimalkan penyediaan jasa layanan bagi masyarakat. Korea Selatan merupakan negara yang selalu masuk dalam 10 terbaik penerapan eGovernment di dunia.

Ada beberapa best practice penerapan e-gov di Korea Selatan yang dapat dijadikan contoh untuk negara Indonesia. EParticipation adalah salah satu bentuk e-gov yang dapat digunakan masyarakat Korea Selatan untuk dapat menyamapaikan kritik, saran dan keluhannya dan aspirasi yang mereka sampaikan dapat mempengaruhi pengambilan keputusan Pemerintah. E-post situs ini menawarkan layanan pos dengan kepercayaan masyarakat terhadap kinerja pemerintah semakin meningkat.

Melihat kondisi tersebut pemerintah berusaha memperbaiki tata kelola pemerintahan demi meningkatkan pelayanan publik dan pemertaan pembangunan, sehingga mengurangi atau bahkan memberantas praktik-praktik korupsi. Selain itu dalam meningkatkan indeks persepsi korupsi membutuhkan kontribusi dari berbagai pihak tidak hanya pemerintah saja namun juga masyarakat dan dunia usaha.

nyaman dan aman seperti Pos, Pengiriman, EMS Belanja, Pasar terbuka yang dapat diakses kapan pun dan dimanapun tanpa perlu mengunjungi kantor pos. Worknet, webiste yang menyediakan informasi lowongan pekerjaan yang dibutuhkan oleh seluruh masyarakat Korea Selatan. Dalam membernatas korupsi pemerintah Kota Seoul megembangkan sistem OPEN yang membuat dampak besar terhadap transparansi publik untuk pengambilan keputusan dan tindakan individu PNS.

Sementara di Indonesia sendiri beberapa daerah cukup kreatif dan inovatif dalam menerapkan e-government. Ada beberapa daerah yang sudah menerapkan egovernment dengan baik. Pemerintah Kabupaten Seragen. Kabupaten Sragen mengembangkan "One Stop Service 
(OSS)", dengan menerapkan OSS, pembuatan perijinan tidak lagi berbelit-belit karena proses perijin cukup berhenti di satu atap.

Pemerintah Kota Surabaya yang terkenal dengan penerapan e-Procurement, e-gov ini hadir karena sistem pengadaan barang dan jasa yang masih dilakukan secara manual, sehingga kurang efektif dan efisien. Selain itu marak terjadinya korupsi dalam pelaksaaa barang dan jasa dengan sistem manual. SI UPIK merupakan respon

\section{DAFTAR PUSTAKA}

Bakunzibake, P., Klein, G. O., \& Islam, S. M. (2019). E-government implementation and monitoring: The case of Rwanda's 'one-stop'Egovernment. The Electronic Journal of Information Systems in Developing Countries, 85(5), e12086.

Choi, H., Park, M. J., Rho, J. J., \& Zo, H. (2016). Rethinking the assessment of e-government implementation in developing countries from the perspective of the design-reality gap: Applications in the Indonesian eprocurement system. Telecommunications Policy, 40(7), 644-660.

Darmawan, E. (2018). E-Readiness Provinsi Kepulauan Riau dalam Penerapan E-Government (Studi Terhadap Kepri Smart province). KEMUDI: Jurnal Ilmu Pemerintahan, 3(1), 173-192.

Fadhlurrahman, R., Saputra, M. C., \& Herlambang, A. D. (2018). Evaluasi Penerapan E-government Di Pemerintah Kota Batu Menggunakan Kerangka Kerja pemerintah Kota Yogyakarta terhadap masyarakat dalam menjawab keluhan dan kebutuhan masyarakat akan pelayanan dan kinerja pemerintah.

Dampak penerapan e-government di Indonesia dalam memberantas korupsi membuat, Indeks Persepsi Korupsi Indonesia (IPK) Indonesia pada tahun 2018 naik ke peringkat 4 di tingkat ASEAN setelah berhasil menggeser posisi Thailand yang turun ke posisi 6 .

$\begin{array}{lr}\text { Pemeringkatan } & \text { E-government } \\ \text { Indonesia (PeGI). } & \text { Jurnal } \\ \text { Pengembangan } & \text { Teknologi } \\ \text { Informasi dan Ilmu } & \text { Komputer e- } \\ \text { ISSN, 2548, 964X. }\end{array}$

Glyptis, L., Christofi, M., Vrontis, D., Del Giudice, M., Dimitriou, S., \& Michael, P. (2020). E-Government implementation challenges in small countries: The project manager's perspective. Technological Forecasting and Social Change, 152, 119880.

Kurfalı, M., Arifoğlu, A., Tokdemir, G., \& Paçin, Y. (2017). Adoption of egovernment services in Turkey. Computers in Human Behavior, 66, 168-178.

Lukhitasari, F. (2018). Penerapan Pelayanan Administrasi Kesehatan Berbasis E-Government Melalui Sikda Generik Di Puskesmas Tanggulangin Kecamatan Tanggulangin Kabupaten Sidoarjo (Doctoral Dissertation, Universitas Muhammadiyah Sidoarjo). 
Meacham, S., Rath, P., Moharana,P., Phalp, K. T., \& Park, M. S. (2019). Onestop shop e-government solution for South-Korean government multiministry virtual employmentwelfare plus center system.

Mensah, I. K., Jianing, M., \& Durrani, D. K. (2017). Factors Influencing Citizens' Intention to Use EGovernment Services: A Case Study of South Korean Students in China. International Journal of Electronic Government Research (IJEGR), 13(1), 14-32.

Mohammed, F., Ibrahim, O., Nilashi, M., \& Alzurqa, E. (2017). Cloud computing adoption model for egovernment implementation. Information Development, 33(3), 303-323.

Napitupulu, D., Syafrullah, M., Rahim, R., Amar, A., \& Sucahyo, Y. G. (2018, May). Content validity of critical success factors for e-Government implementation in Indonesia. In IOP Conference Series: Materials Science and Engineering (Vol. 352, No. 1, p. 012058). IOP Publishing.

Nugraha, J. T. (2018). E-Government dan pelayanan publik (Studi Tentang Elemen Sukses Pengembangan EGovernment di Pemerintah Kabupaten Sleman). Jurnal Komunikasi dan Kajian Media, 2(1), 32-42.

Putra, R., Ardhiarisca, O., Wijayanti, R. R., \& Pratiwi, B. Y. (2018). Evaluasi Perkembangan dan Transparansi Laporan Keuangan E-Government Pemerintah Daerah Di Indonesia. In Seminar Nasional Teknologi Informasi dan Komunikasi 2018 (SENTIKA 2018).

Ramli, R. M. (2017). E-government implementation challenges in
Malaysia and South Korea: a comparative study. The Electronic Journal of Information Systems in Developing Countries, 80(1), 1-26. Rufín, R., Bélanger, F., Molina, C.

M., Carter, L., \& Figueroa, J. C. S. (2018).

A cross-cultural comparison of electronic government adoption in Spain and the USA. In Technology adoption and social issues: Concepts, methodologies, tools, and applications (pp. 476-493). IGI Global.

SALSABILA, L., \& PURNOMO, E. P. (2018). Establishing and Implementing Good Practices EGovernment (A Case Study: Indonesia and South Korea EGovernment Implementation 20122016). Journal of Asian Review of Public Affairs and Policy, 3(3).

Teo, T. S., Kim, S. L., \& Jiang, L. (2018). E-learning implementation in south Korea: Integrating Effectiveness and Legitimacy Perspectives. Information Systems Frontiers, 118.

Yunita, N. P., \& Aprianto, R. D. (2018). Kondisi Terkini Perkembangan Pelaksanaan E-Government di Indonesia: Analisis Website. In Seminar Nasional Teknologi Informasi dan Komunikasi (pp. 329-336).

Yusuf, R. M. S., \& Jumhur, H. M. (2018). Penerapan E-government Dalam Membangun Smart City Pada Kota Bandung Tahun 2018. eProceedings of Management, 5(3).

Viona, J., Asrinaldi, A., \& Valentina, T. R. (2019). TRANSFORMASI PENYELENGGARAAN PEMERINTAHAN

BERBASISKAN

EGOVERNMENT (Studi Kasus: Kendala Pemerintah Kota Padang 
Dalam Penerapan e-Government). MEDIA BINA ILMIAH, 14(4), 2413-2420.

Vo, T. T. T., Lee, J. K., Lee, S., Gim, G., \& Kim, J. B. (2016). A Study on the

\section{PROFIL SINGKAT}

Penulis pertama Diah Wahyuningsih, S.IP adalah mahasiswa Magister Ilmu Pemerintahan Universitas Yogyakarta. Pendidikan formal Penulis dilalui di SDN Harjowinangun, SMP N 1 Belitang, SMA N 1 Belitang, S1 Ilmu Pemerintahan Universitas Muhammadiyah Yogyakarta.

Penulis kedua Eko Priyo Purnomo, M.Res., Ph.D merupakan dosen Magister Ilmu Pemerintahan dan S1 Program Studi Ilmu Pemerintahan Universitas Muhammadiyah Yogyakarta. Riwayat Pendidikan Penulis yaitu S1 Ilmu Pemerintahan Universitah Gadjah Mada, S2 Ilmu Politik Universitas Gadjah Mada, dan S3 Politik Lingkungan dan Kebijakan Publik, University of Leeds United Kingdom.
Effect of the National Culture on the E-government Usage Behavior in Vietnam. International Information Institute (Tokyo). Information, 19(7A), 2613. 